\section{Randomised clinical trial of intravitreal Avastin vs photodynamic therapy and intravitreal triamcinolone: long-term results}

S Sacu', S Michels², F Prager', G Weigert ${ }^{1,3}$, R Dunavoelgyi', W Geitzenauer ${ }^{1}$, C Pruente $^{1}$ and U Schmidt-Erfurth'

\begin{abstract}
Purpose To compare 1-year functional and anatomic outcomes of intravitreal bevacizumab (IVB) and photodynamic therapy plus intravitreal triamcinolone (PDT + IVTA) combination in patients with neovascular age-related macular degeneration (AMD). Methods In this prospective, randomised, controlled clinical trial, 28 patients were included. All patients were randomised 1:1 to $0.04 \mathrm{ml} / 1 \mathrm{mg}$ of IVB or PDT plus same day $0.1 \mathrm{ml} / 4 \mathrm{mg}$ IVTA (PDT + IVTA). Follow-up examinations were performed in monthly intervals in IVB group and every 3 months in PDT + IVTA group. Main outcomes were change in mean visual acuity (VA), mean central retinal thickness (CRT) and the mean number of treatments.

Results At month 12, mean VA improved to a 1.5-line gain in IVB group, and lost three letters in PDT + IVTA group $(P=0.02)$. Mean CRT was reduced from $357 \mu \mathrm{m}$ at baseline to $244 \mu \mathrm{m}$ at month 12 in IVB group and from $326 \mu \mathrm{m}$ to $254 \mu \mathrm{m}$, respectively, in PDT + IVTA group $(P=0.8)$. The mean number of treatments was 6.8 in the IVB group $v s 1.9$ in the PDT + IVTA group. No significant local or systemic safety concerns were detected during follow-up time.

Conclusions Patients treated with IVB showed a significant better VA outcome compared with the PDT + IVTA group despite the fact that both modalities showed equal potency in reducing CRT during a 12-month period.
\end{abstract}

Eye (2009) 23, 2223-2227; doi:10.1038/eye.2008.423; published online 23 January 2009

Keywords: intravitreal bevacizumab; age-related macular degeneration; photodynamic therapy; triamcinolone acetonide

Introduction

Vascular endothelial growth factor (VEGF) is a very potent vascular endothelial cell mitogen and has been implicated as the major angiogenic stimulus responsible for neovascularisation in age-related macular degeneration (AMD). ${ }^{1,2}$ Recently, patients treated with ranibizumab (Lucentis ${ }^{\circledR}$ ) monotherapy for AMD have shown stabilisation, and a 3-line improvement in visual acuity (VA) in about $34-40 \%$ of patients. ${ }^{3}$ However, the first phase III studies evaluating ranibizumab therapy were based on monthly injections. ${ }^{3,4}$

Bevacizumab (Avastin ${ }^{\mathbb{R}}$ ), a full-length monoclonal antibody binding all isoforms of VEGF, has been basically developed as a systemic antiangiogenic drug in oncology. However, intravenous administration of bevacizumab in clinical trials has been shown to be effective in the treatment of neovascular AMD. ${ }^{5}$ Hence, bevacizumab was administered intravitreally as an off-label treatment option for neovascular AMD. ${ }^{5}$ Although bevacizumab is a relatively large antibody $(\sim 150 \mathrm{kD})$, studies reported that it penetrates the retina. ${ }^{6}$ Thereupon several studies evaluating the effectiveness of off-label treatment with
'Department of Ophthalmology, Medical University of Vienna, Vienna, Austria

${ }^{2}$ Department of Ophthalmology, University of Zurich, Zurich, Switzerland

${ }^{3}$ Department of Clinical Pharmacology, Medical University of Vienna, Vienna, Austria

Correspondence: S Sacu, Department of Ophthalmology, Medical University of Vienna, Waehringer Guertel 18-20, 1090 Vienna, Austria Tel: + 431404007931 ; Fax: +431404007932. E-mail: stefan.sacu@ meduniwien.ac.at

Received: 12 August 2008 Accepted in revised form: 15 December 2008 Published online: 23 January 2009

Ursula Schmidt-Erfurth, MD, is an owner of the patent on the use of green porphyrins in neovasculature of the eye under the guidelines of the Wellman Laboratories of Photomedicine, Harvard Medical School, Boston, MA, USA. 
intravitreal bevacizumab (IVB) have been performed. ${ }^{7,8}$ Despite the lack of any randomised trial data and the frequent requirement for re-treatment, IVB has become a popular treatment for neovascular AMD.

Recently, the authors reported 6-month outcomes from a randomised, controlled, single centre clinical trial of IVB $v s$ photodynamic therapy combined with an intravitreal injection of triamcinolone (PDT + IVTA) conducted among patients with neovascular AMD. ${ }^{9}$ This study reports the long-term efficacy and safety of $1 \mathrm{mg}$ (0.04 ml) IVB vs PDT plus same day $4 \mathrm{mg}(0.1 \mathrm{ml})$ IVTA for neovascular AMD.

\section{Materials and methods}

This study is an open label, single centre, randomised, controlled clinical trial. The study protocol was approved by the Ethics Committee of the Medical University of Vienna. The study was registered at the European Clinical Trials Database (EudraCT no. 2005-003288-21) and adhered to the guidelines of the declaration of Helsinki. All patients signed written informed consent before enrollment. Detailed information on inclusion and exclusion criteria, patient evaluation, and the treatment protocol for this study were described in an earlier report. ${ }^{9}$ Briefly, patients with neovascular AMD of any lesion type were included. Inclusion criteria were any lesion type smaller than four disc areas, no prior treatment for neovascular AMD, and a VA of 20/40-20/ 800. Patients with a history of thromboembolic events within the last 3 months and predictable need for ocular surgery were not included in the study. Patients were randomised $1: 1$ to $1 \mathrm{mg}$ IVB or standard verteporfin PDT $\left(6 \mathrm{mg} / \mathrm{m}^{2}, 50 \mathrm{~J} / \mathrm{cm}^{2}, 600 \mathrm{~mW} / \mathrm{cm}^{2}, 83 \mathrm{~s}\right.$ light application) plus same day $4 \mathrm{mg}$ IVTA. After 3 initial injections of $1 \mathrm{mg}(0.04 \mathrm{ml})$ bevacizumab at monthly intervals, re-treatment was based on findings of OCT only. Indication for re-treatment after the third injection was an evidence of persistent or recurrent intra- or subretinal fluid by OCT. A stable pigment epithelial detachment without these findings was no indication for retreatment. Patients in the PDT + IVTA group were retreated at 3 months intervals if there was evidence for leakage by fluorescein angiography (FA).

\section{Outcome measures}

A complete ophthalmologic examination, measurement of best-corrected VA (BCVA) according to the protocol established for the early treatment diabetic retinopathy study (ETDRS) charts at $2 \mathrm{~m}$, StratusOCT, FA, indocyanine green angiography (ICGA), and a complete ophthalmic examination were evaluated at baseline, months 3, 6, and 12. Patients randomised to IVB were seen in monthly interval.
Primary and secondary outcomes were change in mean VA and mean $1 \mathrm{~mm}$ central retinal thickness (CRT) comparing both treatment groups.

\section{Statistical analysis}

For statistical analysis repeated measure ANOVA was used to compare mean VA and mean CRT of both treatment arms. For comparison of VA and CRT outcomes within each group to baseline, the $t$-test was used. $P$-values of $<0.05$ were considered statistically significant.

\section{Results}

\section{Study population and statistical power}

A total of 28 patients, 19 women and 9 men, were included in the study (14 into each arm). A power calculation, based on the $a$ priori assumption of an average sigma (SD of repeated measurements) of 0.19 for mean VA and of a two-sided $\alpha=0.05$ and a $\beta=0.20$, revealed that this study with 14 patients per group had the statistical power of $80 \%$ to detect a minimum difference of $20 \%$ between groups.

The mean age was $78 \pm 8$ years (range: $58-88$ ). Baseline characteristics were well balanced with regard to VA and CRT $(P>0.05)$. Mean VA in the bevacizumab-treated group was 50 vs 46 letters in the PDT + IVTA $(P=0.58)$. Mean CRT in the bevacizumab-treated group was $357 \mu \mathrm{m}$ vs $326 \mu \mathrm{m}$ in the PDT + IVTA group $(P=0.48)$. Upto month 12 , no patient was excluded from the study, and at month 12 , the follow-up was $100 \%$ in the bevacizumabtreated group. One patient failed to follow-up at month 12 in the PDT + IVTA-treated group.

\section{VA outcome and number of treatments}

Mean VA in bevacizumab-treated eyes improved from 50 letters $(20 / 100)$ at baseline to 62 letters $\left(20 / 63^{+2}\right)$ at month 3, 61 letters $\left(20 / 63^{+1}\right)$ at month 6,58 letters $\left(20 / 63^{-2}\right)$ at month 9 , and 58 letters $\left(20 / 63^{-2}\right)$ at month 12. In the bevacizumab group, mean VA increased significantly from baseline at each follow-up time (Figure 1 top, $P<0.01$ ).

In the PDT + IVTA-treated eyes, VA showed a stable course from 46 letters $\left(20 / 125^{+1}\right)$ at baseline to 46 letters $\left(20 / 125^{+1}\right)$ at months 3 and 6 , and then showed a slightly decrease to $45(20 / 125)$ letters at month 9 , and 43 $\left(20 / 125^{-2}\right)$ letters at month 12 (Figure 1 top, $P>0.05$ ). The time course of mean VA is shown in Figure 1.

There was a significant difference in mean VA between groups ( $P=0.02$, ANOVA) in favour of the bevacizumabtreated eyes. Table 1 and Figure 1 (bottom) show the distribution of change in VA for both groups. 

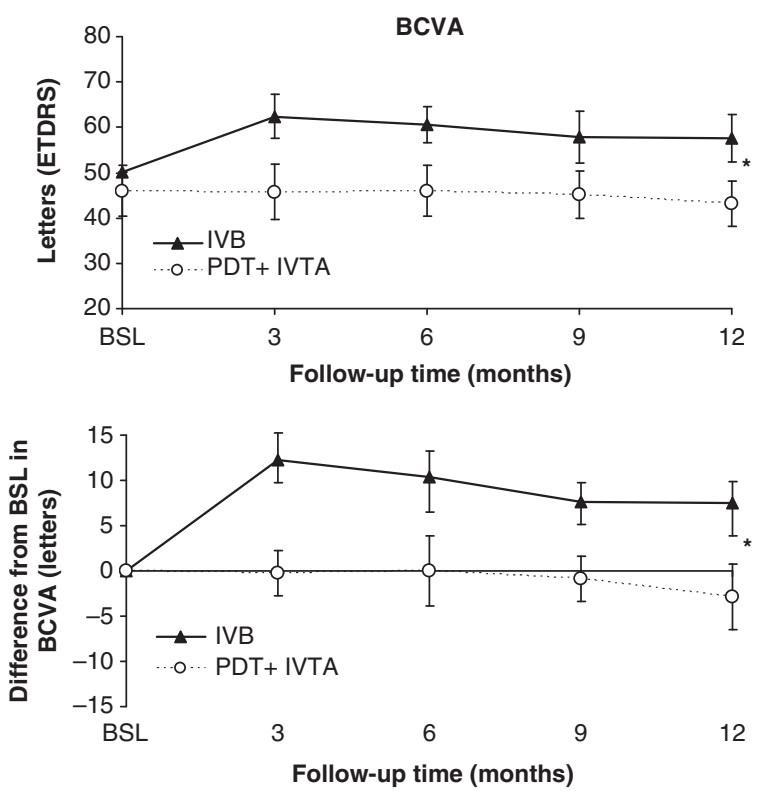

Figure 1 Time course of best-corrected visual acuity (BCVA) in 12 months follow-up comparing $1 \mathrm{mg}$ intravitreal bevacizumab (IVB) to PDT plus $4 \mathrm{mg}$ intravitreal triamcinolone (PDT + IVTA; top). Absolute change in BCVA compared with baseline (BSL; bottom). Data are presented as mean \pm SEM. ${ }^{*} P<0.05$ between groups (ANOVA)

Table 1 Frequency distribution of changes in BCVA from BSL to 6 and 12 months

\begin{tabular}{|c|c|c|c|c|}
\hline \multirow[t]{3}{*}{ Change in BCVA } & \multicolumn{4}{|c|}{ Eyes [n (\%)] } \\
\hline & \multicolumn{2}{|c|}{$I V B(\mathrm{n}=14)$} & \multicolumn{2}{|c|}{$P D T+I V T A(\mathrm{n}=14)$} \\
\hline & Month 6 & Month 12 & Month 6 & Month 12 \\
\hline$\geqslant 3$-line increase & $5(36)$ & $4(29)$ & $3(21)$ & $1(7)$ \\
\hline $0-<3$-line increase & $7(50)$ & $7(50)$ & $4(29)$ & $4(29)$ \\
\hline$<3$-line decrease & $2(14)$ & $3(21)$ & $5(36)$ & $7(50)$ \\
\hline$\geqslant 3$-line decrease & $0(0)$ & $0(0)$ & $2(14)$ & $2(14)$ \\
\hline
\end{tabular}

$\mathrm{BCVA}=$ best-corrected visual acuity; $\mathrm{BSL}=$ baseline; $\mathrm{IVB}=$ intravitreal bevacizumab; IVTA = intravitreal triamcinolone; $\mathrm{PDT}=$ photodynamic therapy.

The mean number of treatments including month 12 was 6.8 out of 13 possible treatments in the bevacizumab-treated group and 1.9 out of 5 possible treatments in the PDT + IVTA-treated group. At month 6, $50 \%$ required re-treatment in the bevacizumab group and $14 \%$ in the PDT + IVTA group. At month $12,43 \%$ needed re-treatment in the bevacizumab group, whereas no patient had retreated in the PDT + IVTA group.

\section{CRT}

Mean CRT showed a marked decrease from baseline to month 3 followed by stabilisation up to month 12 in both groups. In the bevacizumab-treated group,
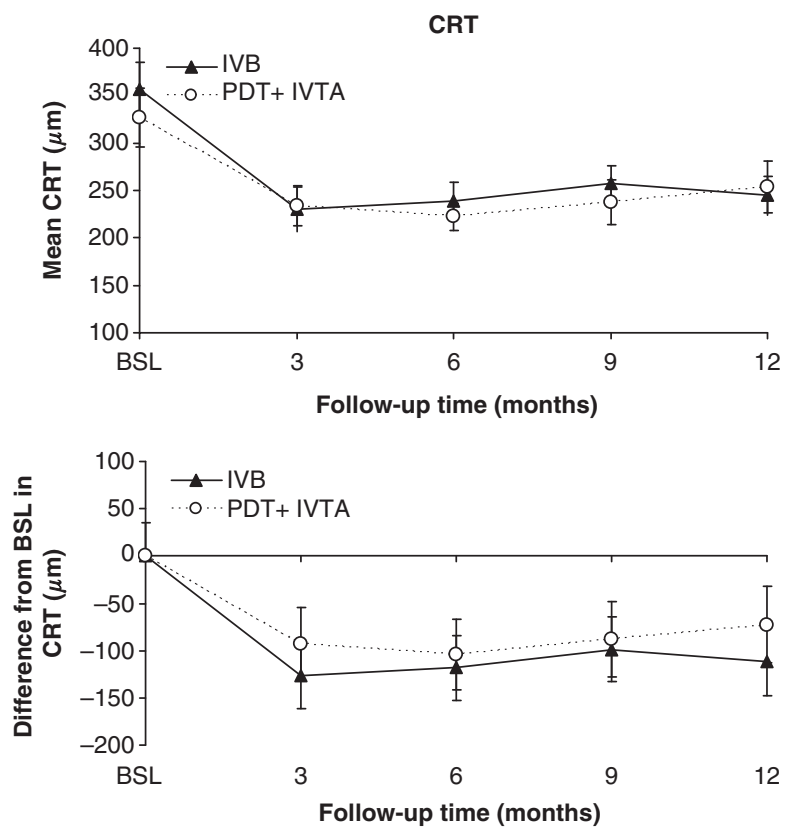

Figure 2 Time course of central retinal thickness (CRT) in 12 months follow-up comparing $1 \mathrm{mg}$ intravitreal bevacizumab (IVB) to PDT plus $4 \mathrm{mg}$ intravitreal triamcinolone (PDT + IVTA; top). Absolute change in CRT compared with baseline (BSL; bottom). Data are presented as mean \pm SEM.

mean CRT, decreased from 357 to $230 \mu \mathrm{m}$ at month 3, was stable at month $6(239 \mu \mathrm{m})$ and again increased slightly to $257 \mu \mathrm{m}$ at month 9 and $244 \mu \mathrm{m}$ at month 12 (Figure 2 top). Compared to baseline, the decrease in mean CRT became statistically significant as early as month $3(P<0.005)$. In the PDT + IVTA group, mean CRT decreased from $326 \mu \mathrm{m}$ at baseline continuously to $234 \mu \mathrm{m}$ at month $3,222 \mu \mathrm{m}$ at month 6 , and then slightly increased to $238 \mu \mathrm{m}$ at month 9 and $254 \mu \mathrm{m}$ at month 12 (Figure 2 top). No significant difference was found between both groups ( $P=0.8$, ANOVA) in mean CRT. Figure 2 bottom shows mean change in CRT for both groups.

No significant correlation was found between changes in VA and changes in CRT in both study groups. Pearson correlation coefficients between VA and CRT changes were $r=-0.5 ; P=0.066$ at month $3, r=-0.47 ; P=0.089$ at months 6 and month 9, $r=-0.32 ; P=0.26$ at month 12 in the IVB group, and $r=-0.24 ; P=0.42, r=-0.1 ; P=0.74$, $r=-0.16 ; P=0.58$, and $r=0.19 ; P=0.5$, respectively in the PDT + IVTA-treated group.

\section{Safety}

In none of the groups any severe ocular (eg, traumatic cataract, retinal detachment, endopthalmitis, severe ocular inflammation, and severe vision loss $>6$ lines) or 
systemic adverse event was reported up to month 12 . In the bevacizumab group, no significant cataract progression was noted within 12 months follow-up, whereas in two patients from PDT and IVTA groups, cataract surgery was performed. A transient IOP rise ( $>25 \mathrm{mmHg}$ ) was observed in two patients at 1 week, treated with a local antiglaucoma therapy. ${ }^{9}$ ICGA showed no evidence for significant bevacizumabassociated choroidal perfusion changes. Patients in the PDT + IVTA group had characteristic post-treatment hypofluorescence within the area of the PDT treatment spot, but there was no evidence for treatment-associated choroidal hypoperfusion outside the area of the PDT treatment spot.

\section{Discussion}

The result of this study shows the high efficacy of both treatments, bevacizumab monotherapy, and combination therapy using PDT + IVTA in reducing CRT in exudative AMD. Both treatments were equally potent to reduce intravitreal fluid with regard to extent and time course of CRT reduction. However, a significant difference of both treatment modalities was found for BCVA results.

Patients treated with anti-VEGF monotherapy showed a significant better BCVA outcome compared with the combination group despite the fact that both modalities showed equal potency in reducing CRT.

Various reasons have to be considered to explain these findings. There might be a different time course of retinal fluid reduction during the first 3 months with continuing retinal damage in the combination group, due to delayed fluid resorption or even temporarily increase in intraretinal fluid just after treatment. Case series using bevacizumab have shown a very rapid fluid resorption during the first week after injection. ${ }^{7}$ However, this study was set up following the routine clinical control schedule at the area of PDT treatment with 3-month intervals.

On the other hand, it has been shown that PDT results in transient choroidal hypo- or non-perfusion. PDT activates inflammatory cytokines as well as inflammatory cells. ${ }^{10,11}$ Both effects might contribute to increased and persistent damage of RPE or photoreceptor cells, which potentially explain the inferior BCVA result in the combination group. Furthermore, it was shown that triamcinolone may have a toxic effect on RPE cells, although its anti-inflammatory and antiangiogenetic properties may to beneficial to avoid side effects of the PDT treatments. ${ }^{12,13}$ All of these factors may contribute to the less favourable BCVA outcomes in the combination group.

Despite significantly worse vision result in the PDT + IVTA group in comparison with IVB group, considering to re-treatment frequency, the combination of
PDT and triamcinolone seems to result in a relatively stable outcome with inactivation of the CNV and only minimal need for re-treatment. The overall re-treatment rate in the combination group was 1.9 treatments, compared with 6.9 treatments in the anti-VEGF group. This potency of the combination treatment to create a stable and in many patients probably finate end point warrants further investigations into the combination of PDT, triamcinolone, and anti-VEGF as limiting the need for re-treatment is a relevant demand in actual treatment approaches using anti-VEGF monotherapies.

Another treatment strategy of neovascular AMD is the use of PDT and VEGF inhibitions. ${ }^{14-16}$ Use of an antiangiogenic factor can counteract the PDT-induced overexpression of VEGF and reduce its adverse effects. Two-year outcomes of FOCUS (RhuFab V2 ocular treatment combining the use of visudyne to evaluate safety) study showed that PDT combined with intravitreal ranibizumab was more effective than PDT alone in patients with predominantly classic CNV secondary to AMD, and that ranibizumab treatment reduced the need for re-treatment with PDT. ${ }^{14}$ In the FOCUS study, patients in the combination group received a $0.5-\mathrm{mg}$ ranibizumab for up to a total of 24 injections in 2 years. At month 24, 25\% of PDT plus ranibizumab combination patients had gained $\geqslant 15$ letters (vs 7\% for PDT alone), and the two treatment arms differed by 12.4 letters in mean VA change. ${ }^{14} \mathrm{~A}$ combination treatment of PDT and IVB injections shows promising results. In a prospective case series, Ahmadieh et $a l^{15}$ described significant better BCVA after a combination treatment with single-session PDT followed by $1.25 \mathrm{mg}$ IVB injection at month 6 . In a retrospective study, Dhalla et $a l^{16}$ observed an improvement in BCVA in $67 \%$ and need for re-treatment in $37 \%$ of patients treated with combined PDT and $1.25 \mathrm{mg}$ IVB. In our study, $43 \%$ of patients needed re-treatment in the bevacizumab group, whereas no patient had retreated in the PDT + IVTA group at month 12 .

To conclude, further studies including more patients are needed to verify these promising results after treatment with IVB. Furthermore, a reduction of re-treatment frequency without impairment of the VA results is desirable. Ongoing studies will have to evaluate whether the combination of PDT with anti-VEGF treatment can provide some efficacy with regard to VA results as anti-VEGF monotherapy. The results of this study suggest putting a special focus on this question.

\section{References}

1 Kvanta A, Algvere PV, Berglin L, Seregard S. Subfoveal fibrovascular membranes in age-related macular 
degeneration express vascular endothelial growth factor. Invest Ophthalmol Vis Sci 1996; 37: 1929-1934.

2 Lopez PF, Sippy BD, Lambert HM, Thach AB, Hinton DR. Transdifferentiated retinal pigment epithelial cells are immunoreactive for vascular endothelial growth factor in surgically excised age-related macular degeneration-related choroidal neovascular membranes. Invest Ophthalmol Vis Sci 1996; 37: 855-868.

3 Rosenfeld PJ, Brown DM, Heier JS, Boyer DS, Kaiser PK, Chung CY, et al., MARINA Study Group. Ranibizumab for neovascular age-related macular degeneration. $N$ Engl J Med 2006; 5: 1419-1431.

4 Kaiser PK, Brown DM, Zhang K, Hudson HL, Holz FG, Shapiro $\mathrm{H}$ et al. Ranibizumab for predominantly classic neovascular age-related macular degeneration: subgroup analysis of first-year ANCHOR results. Am J Ophthalmol 2007; 144: 850-857.

5 Fung AE, Rosenfeld PJ, Reichel E. The international intravitreal bevacizumab safety survey: using the internet to assess drug safety worldwide. Br J Ophthalmol 2006; 90: 1344-1349.

6 Shahar J, Avery RL, Heilweil G, Barak A, Zemel E, Lewis GP et al. Electrophysiologic and retinal penetration studies following intravitreal injection of bevacizumab (Avastin). Retina 2006; 26: 262-269.

7 Goff MJ, Johnson RN, McDonald HR, Ai E, Jumper JM, $\mathrm{Fu} \mathrm{A}$. Intravitreal bevacizumab for previously treated choroidal neovascularization from age-related macular degeneration. Retina 2007; 27: 432-438.

8 Aisenbrey S, Ziemssen F, Völker M, Gelisken F, Szurman P, Jaissle $\mathrm{G}$ et al. Intravitreal bevacizumab (Avastin) for occult choroidal neovascularization in age-related macular degeneration. Graefes Arch Clin Exp Ophthalmol 2007; 245: 941-948.

9 Weigert G, Michels S, Sacu S, Weigert G, Polak K, Vécsei-Marlovits PV et al. Intravitreal bevacizumab (Avastin) therapy versus photodynamic therapy plus intravitreal triamcinolone for neovascular age-related macular degeneration: 6-month results of a prospective, randomised, controlled clinical study. Br J Ophthalmol 2008; 92: 356-360.

10 Schmidt-Erfurth U, Schlötzer-Schrehard U, Cursiefen C, Michels S, Beckendorf A, Naumann GO. Influence of photodynamic therapy on expression of vascular endothelial growth factor (VEGF), VEGF receptor 3, and pigment epithelium-derived factor. Invest Ophthalmol Vis Sci 2003; 44: 4473-4480.

11 Schmidt-Erfurth UM, Michels S. Changes in confocal indocyanine green angiography through two years after photodynamic therapy with verteporfin. Ophthalmology 2003; 110: 1306-1314.

12 Chang YS, Wu CL, Tseng SH, Kuo PY, Tseng SY. Cytotoxicity of triamcinolone acetonide on human retinal pigment epithelial cells. Invest Ophthalmol Vis Sci 2007; 48 2792-2798.

13 Oh J, Jung YS, Kim GS, Oh IK, Rho BK, Huh K. The effect of short-term exposure of triamcinolone acetonide on fibroblasts and retinal pigment epithelial cells. Acta Ophthalmol Scand 2007; 85: 786-790.

14 Antoszyk AN, Tuomi L, Chung CY, Singh A, on behalf of the FOCUS STUDY GROUP. Ranibizumab combined with verteporfin photodynamic therapy in neovascular age-related macular degeneration (FOCUS): year 2 results. Am J Ophthalmol 2008; 145: 862-874.

15 Ahmadieh H, Taei R, Soheilian M, Riazi-Esfahani M, Ahadi H. Single-session photodynamic therapy combined with intravitreal bevacizumab for neovascular age-related macular degeneration. Eur J Ophthalmol 2008; 18: 297-300.

16 Dhalla MS, Shah GK, Blinder KJ, Ryan Jr EH, Mittra RA, Tewari A. Combined photodynamic therapy with verteporfin and intravitreal bevacizumab for choroidal neovascularization in age-related macular degeneration. Retina 2006; 26: 988-993. 